\title{
Bireylerin Gençlik Merkezi Faaliyetlerine Yönelik Tutum Düzeylerinin İncelenmesi: (Elazığ İli Örneği)
}

\author{
Investigation of Attitude Levels of Individuals towards Youth Center Activities: (Sample of Elazl $\breve{g}$ \\ Province)
}

\author{
Metin Yildı* - Abdurrahman Kirtepe ${ }^{* *}$
}

\begin{abstract}
It is important for young people to stay away from harmful habits in terms of being able to demonstrate their own abilities by participating in sportive, social, cultural and artistic activities. In this context, youth centers have undertaken a great responsibility. In order to apply the scales in the study and to collect the data, the approval of the Social and Human Research Ethics Committee of Firat University was obtained from the ethics committee with the date of 14.05.2020 and the 10th meeting and the decision number 7. The purpose of this study is to examine the attitude levels of individuals towards youth center activities. The universe of the research consists of 1750 people who visited Elazig Youth Center once in the last year. The sample group of the study is 244 people .It was determined that the data were suitable for normal distribution. Comparison was made by using independent sample $\mathrm{T}$ test for comparing variables with scale scores with two categories, and one-way analysis of variance (One-Way ANOVA) for comparing variables with more than two categories with scale scores. In case the difference is detected as a result of one-way analysis of variance; using the Bonferroni Test, one of the post-hoc methods, it was determined which category or categories originated from the difference. In the study, it was taken as $\alpha=0.05$. As a result of the findings; it was observed that individuals' gender did not make a significant difference in their attitudes towards their activities in their youth centers, and their economic status was not an important factor for individuals with lower financial status to participate in these activities. It has been observed that individuals with higher education level participate more in the activities, individuals who do not work in any job, take more time to participate in activities in this center voluntarily, and as the level of participation of individuals in activities in the youth center increases, their volunteering status also increases.
\end{abstract}

Structured Abstract: Introduction Considering that some of the definitions made on youth deal with young people in terms of age categories, while others consider the characteristics of the youth period, youth with the definition made by age range; For some, it covers a period starting at the age of 12-25, for others 15-29, and for others at the age of 18 and extending to the age of 35.(Atl 2006) Evaluation of free time in the best way and the most important organization providing areas to benefit from these facilities in Turkey is the Youth and Sports Ministry. In the provinces, the Youth Centers established within the Provincial Directorates of Youth Services and

\footnotetext{
* Dr. Sportif Eğitim Uzmanı, Gençlik ve Spor Bakanlığı, Elazığ Gençlik ve Spor İl Müdürlüğü, Spor Yönetimi Dr, Sports Training Specialis, Ministry of Youth and Sports Provicial Directorate, Sports Management ORCID 0000-0003-0926-9965 metinyildiz.2323@gmail.com

** Doç., Dr. Öğretim Üyesi, Fırat Üniversitesi, Spor Bilimleri Fakültesi, Rekreasyon Bölümü Assoc Prof. Dr. Faculty Member, Firat University, Sports Science Faculty, Recreation Depertment ORCID 0000-0003-3268-2192

abdurrahmankirtepe@gmail.com

Cite as/ Atıf: Yıldız, M. \& Kırtepe, A. (2020). Bireylerin gençlik merkezi faaliyetlerine yönelik tutum düzeylerinin incelenmesi: (Elazı̆̆ ili örneği), Turkish Studies - Social, 15(5), 2757-2768. https://dx.doi.org/10.47356/TurkishStudies.44110

Received/Geliş: 09 June/Haziran 2020

Accepted/Kabul: 20 August/Ağustos 2020

Copyright $($ INTAC LTD, Turkey

Checked by plagiarism software Published/Yayın: 30 August/Ağustos 2020 CC BY-NC 4.0
} 
Sports. It is clear that youth centers, which are defined as organizations that provide opportunities for young people to evaluate their free time within the framework of social, cultural and sports activities, and when they examine their goals and types of activities, can clearly see that young people perform important tasks in their multi-faceted development and their free time (Aycan, 2005).

Purpose of the Research The aim of this study is to examine the attitude levels of individuals towards youth center activities in terms of different variables.

\section{Materials and Methods}

Research Model: The model of this research is the relational screening model, which is one of the quantitaive research methods.

Data Collection Tools: The questionnaire used as a data collection tool in the study consists of two parts. In the first part, questions determining the socio-demographic characteristics of the youth center members prepared by the researchers were included. (age, gender, educational background, income level, time spent in youth center, working status etc.). In the other part of the questionnaire, "Attitude Scale for Youth Centers Activities",(ASFYCA) which was developed by Ataç vd(2018), consisting of 18 questions and 2 sub-dimensions, was used. ASFYCA consists of 18 items and includes 2 sub-dimensions, namely participation (14 items), volunteering (4 items).

Universe and Sampling: The universe of the research consists of 1750 people who visited Elazig Youth Center in the last year. The number of people to be included in the study was calculated with the help of the formula $\mathrm{n}=\frac{N \cdot \sigma^{2} \cdot z^{2}}{d^{2} \cdot(N-1) \cdot+z^{2} \cdot \sigma^{2}}($ Özdamar,2003) As a result of the calculations, it was concluded that 316 people were included in the sample. In the research, questionnaires were applied to 350 people with the method of "sampling in easy" and 344 of them were included in the evaluation.

Data Analysis: It was determined that the data were suitable for normal distribution and comparing variables with two categories with scale scores, independent sample $\mathrm{T}$ test, comparing variables with more than two categories with scale scores, using one-way analysis of variance analysis.(One-Way WANOVA) In case the difference is detected as a result of one-way analysis of variance; Using the Bonferroni Test, one of the post-hoc methods, it was determined which category or categories originated from the difference. In the study, it was taken as $\alpha=0.05$.

Conclusion and Suggestions: It was observed that there was no significant difference in the attitudes of youth center activities according to the gender of the youth included in the study in terms of volunteering, participation dimensions and scale total.(Chart 2). According to the results obtained from a study, there is no statistically significant difference between the affective expression, affective sensitivity, affective control, social expressionism, social sensitivity, social control and social skill total female and male score averages from the social skill sub-dimensions of the social skill levels of the individuals participating in the leisure activities in the youth center.(Keleş 2017).

It was conducted by Ataç Ö (2018) in a different study and it was observed that there was no significant difference in the attitudes of youth towards youth center activities according to their gender in terms of volunteering and participation.

It is thought that this is due to the fact that the participating youth have different socio-demographic characteristics. It was seen that there was a significant difference between the attitude and volunteerism dimensions of the attitudes of the youth income status of the young people participating in the study and the total scores of the scale. According to this, it was observed that the youth with a income level of $3000 \mathrm{TL}$ and below had the highest scores in volunteering and participation dimensions.(Chart 4) According to the results of the research carried out by Örteş (2010), only one out of every four respondents stated that their economic situation was an obstacle to evaluating their free time, while three stated that they did not. Considering that in our study, young people with lower income levels have higher participation and volunteering scores, it can be said that young people participate in these activities on a voluntary basis and take part in activities in youth centers by improving their motivations.

It was observed that there was a significant difference between the educational attitudes of young people and their attitudes towards activities in youth centers, and the higher the level of education, the higher the 
participation of young people in the activities.(Chart 5) When the research conducted by Fişne (2017) is evaluated according to the educational level, it is seen that the motivation of volunteering in sports shows a significant difference and the highest motivation level is the university students. When the study was evaluated depending on the level of education, it gave the same results as our research. It is thought that the courses and activities organized for young people who are high school graduates in youth centers and who are preparing for university or studying at the university are more intensive as the reason for the higher education level's participation in the youth center activities. Participants who visited once a week or a few days a week were found to have higher participation and volunteer scores than other participants.(Chart 6) In a study that was done by Sönmezoğlu (2014), it was stated that as the membership duration of the youth centers increases and the frequency of going to youth centers increases, the educational and psychological satisfaction levels increase in a similar direction. The research gave the same results as our study. It was observed that the members who did not work in any job had higher scores on the volunteerism and participation sub-dimensions of the scale than the working members (Chart 7).It can be said that the voluntary status of the members who go to the youth center increases as the level of participation of the members who go to the youth center increases due to the fact that the non-working members do not have an occupation or a situation that prevents them from going to the youth center.

As a result of the findings; it was observed that individuals' gender did not make a significant difference in their attitudes towards their activities in their youth centers, and their economic status was not an important factor for individuals with lower financial status to participate in these activities. It has been observed that individuals with higher education level participate more in the activities, individuals who do not work in any job, take more time to participate in activities in this center voluntarily, and as the level of participation of individuals in activities in the youth center increases, their volunteering status also increases.

Keywords: Young, Youth, Youth Center, Activity, Attitude.

Öz: Gençlerin zararlı alışkanlıklardan uzak durmaları sportif, sosyal, kültürel ve sanatsal aktivitelere katılım sağlayarak kendi yeteneklerini ortaya koyabilmeleri açısından önem arz etmektedir. Bu kapsamda Gençlik merkezleri büyük bir sorumluluk üstlenmişlerdir. Bu çalışmanın amacının bireylerin gençlik merkezi faaliyetlerine yönelik tutum düzeylerinin incelenmesi oluşturmaktadır. Araştırmada ölçeklerin uygulanabilmesi ve verilerin toplanabilmesi için Fırat Üniversitesi Sosyal ve Beşeri Araştırmalar Etik Kurulundan 14.05.2020 tarih ve 10.toplantı,7 karar nolu etik kurul onayı alınmıştır. Araştırmanın evreni, Elazığ Gençlik Merkezi'ni son bir yılda ziyaret eden 1750 kişiden oluşmaktadır. Araştırmanın örneklem grubunu 244 kişi oluşturmaktadır. Verilerin normal dağılıma uygunluk gösterdikleri tespit edilmiş ve iki kategori içeren değişkenlerin ölçek puanları ile karşılaştırılmasında bağımsız örneklem $\mathrm{T}$ testi, ikiden çok kategori içeren değişkenlerin ölçek puanları ile karşılaştırılmasında tek yönlü varyans analizi (One-Way ANOVA) yöntemleri kullanılarak karşılaştırmalar yapılmıştır. Tek yönlü varyans analizi sonucunda farklılık tespit edilmesi durumunda; post-hoc yöntemlerden Bonferroni Testi kullanılarak farklılığın hangi kategori ya da kategorilerden kaynaklandığı tespit edilmiştir. Çalışmada $\alpha=0.05$ olarak alınmıştır. Elde edilen bulgular sonucunda; bireylerin cinsiyetlerinin gençlik merkezlerinde etkinliklerine yönelik tutumlarında anlamlı bir farklılık meydana getirmediği, maddi durumu daha düşük seviyede olan bireylerin bu etkinliklere katılmalarında ekonomik durumlarının önemli bir etken olmadığı görülmüştür. Eğitim seviyesi daha yüksek olan bireylerin etkinliklere daha fazla katılım sağladıkları, herhangi bir işte çalışmayan bireylerin bu merkezdeki etkinliklere daha fazla zaman ayırarak gönüllü olarak katılım sağladıkları, bireylerin gençlik merkezinde ki aktivitelere katılım düzeyleri arttıkça gönüllülük durumlarının da bir artış olduğu görülmüştür.

Anahtar kelimeler: Genç, Gençlik, Gençlik Merkezi, Etkinlik, Tutum.

\section{Giriș}

Gençlik, insanlık tarihinden itibaren süregelen somut bir olgu ve kategoridir. İlahi dinler ve özellikle İslâm, Peygamberlerin gençlik dönemlerinin konu edinildiği kıssalar vasıtasıyla gençlere rol model sunmaktadır. Ulus devletlerin tarihsel süreç içerisinde modern zaman öncesine değin gençliği 
yasal bir kategori içerisine almadıkları ve kabul etmedikleri kamu hizmetlerinin yapılması bakımından çocukluk, yetişkinlik ve yaşlılık biçiminde bir ayrım yaptıkları görülmektedir (Özbay, 2015).

Gençlik kavramları ile ilgili literatüre baktığımız zaman çeşitli tanımlamalar yapılmıştır. Bunlardan bazılarına değinecek olursak; Gürses(ler)'in (1997) "gençlik" kavramına yönelik tarifi, belirli bir toplum biçimlenmesinde o toplumsal biçimlenmeyi yüklenen sosyal "sınıf" ve sosyal "tabaka"ların bilimsel çerçevede tanımlanmış ve sınırlandırılmış belirli bir yaş grubu nüfusu şeklindedir. Kara’ya göre (2013) gençlik çağı, zihni ve fikri bakımdan enerjik olduğundan doğru yönlendirildiği takdirde birçok meseleyi çözüme kavuşturacak aksiyon ve beceriye kabildir. Akın'a göre (2014) ise gençlik, insan hayatının en dinamik dönemi ve bir kimlik arayışı, inşası süreci olarak kabul edilmektedir. Gençlik tanımlara bakıldığı zaman gençlik kavramı ile ilgili ortak bir görüş birliğinin olmadığı görülmüştür.

Gençlik kavramı hakkında yapılan tanımlardan bazıları gençliği yaş grupları bakımından, bazıları ise gençlik döneminin özelliklerine göre ele aldığı düşünülürse, yaş aralığına göre yapılan tanımla gençlik; bazılarına göre 12-25, bazılarına göre 15-29, başkalarına göre ise 18 yaşında başlayan 35 yaşına kadar uzanan bir dönemi kapsamaktadır (Atl1, 2006). Birleşmiş Milletler Örgütü gençlik dönemini 12-24 yaş aralığını olarak kabul etmiştir. Avrupa Birliği ise gençlik dönemini 15 - 29 yaş olarak ele almaktadır. Ulusal Gençlik ve Spor Politika Belgemizde ise ülkemizin şartları göz önüne alınarak gençlik politikalarının hedef grubu 14-29 yaş aralığında bulunan bireyler olarak kabul edilmektedir (Gür vd., 2012).Tıpkı gençlik kavramında olduğu gibi gençlik yaşı ile alakalı ortak bir görüş birliğine varılamamıştır. Gençlik belirli bir yaş grubu ile sınırlanamaz. Çoğu araştırıcı bu dönemin 18-30 yaşlar arası yaşandığı görüşündedir. Ancak bu yaşlarda olan tüm insanlar gençlik dönemini yaşamaz. Çünkü gençlik yaşanması zorunlu olan bir dönem değildir (Geçtan, 2019).

Gençlik ve Spor Bakanlığı bünyesinde faaliyet gösteren gençlik merkezleri Türkiye'de serbest zamanın faydalı bir şekilde değerlendirilmesi ve bu firsatlardan istifade edecek alanları sağlayan en önemli teşkilatların başında gelmektedir. Gençlerin sportif, sosyal ve kültürel aktiviteler çerçevesinde serbest zamanlarını değerlendirmelerine imkân sağlayan ve buna uygun ortam yaratan örgütler olarak ifade edilen gençlik merkezlerinin, amaçları ve aktivite çeşitleri incelendiği zaman gençlerin çok yönlü gelişmelerinde ve serbest zamanlarını değerlendirmelerinde önemli görevler yerine getirdikleri görülmektedir (Aycan,2005). Bu çağda zamanı etkin ve verimli kullanmak önemlidir. Gençlerin hür ve kendi ilgi ve istekleri doğrultusunda kullanacakları serbest zamanlarının olması ve bu zamanlarını faal kullanmaları, gençlerin fiziksel, ruhsal, sosyal ve psikolojik yaşamlarına olumlu katkılar sağlayacağı söylenebilir.

Bir başka tanımda ise Milli Eğitim Bakanlığı gençlik merkezlerinin tanımını; Gençlik merkezleri; gençlik ve spor il müdürlüklerine bağlı, gençlerin sportif, sosyal ve kültürel etkinlikler çerçevesinde serbest zamanlarını değerlendirmelerine fırsat veren ve onlara ortam hazırlayan kültürel kurumlardır. Bu merkezler sanat, bilim, spor, karikatür ve el sanatları gibi çok çeşitli alanlarda gençlerin bilgi ve becerilerini artıracak organizasyonlar düzenlemekte ve gençleri ödüllendirmektedir. Gençlik merkezleri ayrıca konferans, panel, sempozyum, yarışma ve diğer etkinliklerle gençleri, zararlı alışkanlıklardan korunmaları için bilgilendirmektedir (MEB, 2011).

Ülkemizde genç nesil sosyal hayata katkı sunan, ekonomik iyileşmede, teknolojik yeniliklerde ve sosyal değişimde kilit rol oynayan, enerjilerinin, hayallerinin, vizyonlarının ve ideallerinin destek bulması gerekli olan bir sınıf olarak görülmelidir. Türkiye' deki genç neslin sadece spor alanında var olduğunu söylemek hatalı ve eksik bir tabirdir. Gençliğin psikomotor, bilişsel, fiziksel gelişimleri ile ergenlik dönemi aşırılık ve enerjikliklerinin daha sağlıklı atlatılması için spor teşkilatlarının organize ettiği spor ile alakalı proje ve programlar hayati rol oynamaktadır. (Dermez, 2008). 
Literatürden elde edilen bilgilerden yola çıkarak, bireylerin gençlik merkezi faaliyetlerine yönelik tutum düzeylerinin farklı değişkenler açısından incelenmesi bu çalışmanın amacını oluşturmaktadır.

\section{Gereç ve Yöntem}

Araştırmada ölçeklerin uygulanabilmesi ve verilerin toplanabilmesi için Frrat Üniversitesi Sosyal ve Beşeri Araştırmalar Etik Kurulundan 14.05.2020 tarih ve 10.toplantı,7 karar nolu etik kurul onayı alınmıştır.

\section{Araştırma Modeli}

$\mathrm{Bu}$ araştırmanın modeli: Nicel araştırma yöntemlerinden biri olan ilişkisel tarama modelidir.

\section{Veri Toplama Araçları}

Çalışmada veri toplama aracı olarak kullanılan anket iki bölümden oluşmuştur. Birinci bölümde araştırmacılar tarafından hazırlanan gençlik merkezi üyelerinin sosyo-demografik özelliklerini belirleyen sorular yer almıştır.(Yaş, cinsiyet, öğrenim durumu, gelir durumu, gençlik merkezinde zaman geçirme süreleri, çalışma durumları v.s). Anketin diğer bölümünde ise Ataç vd., (2018) tarafindan geliştirilen, 18 soru ve 2 alt boyuttan oluşan "Gençlik Merkezleri Faaliyetlerine Yönelik Tutum Ölçeği”" (GMFYTÖ)" kullanılmıştır. Ölçek Kocaeli'de yaşayan 330 gönüllü gence ulaşılmış ve ölçek uygulanmıştır. Açıklayıcı Faktör Analizi (AFA) sonucunda GMFYTÖ, 18 maddeden oluşmakta ve sırasıyla katılım (14 madde), gönüllülük (4 madde) olarak adlandırılan 2 alt boyut içermektedir. Güvenirlik analizleri için Cronbach Alpha testi kullanılmıştır. Ölçeğin Cronbach alpha değerleri; "katılım" boyutunda 93, "gönüllülük" boyutunda" .85 ve ölçeğin tamamında ise.93 olarak bulunmuştur.

\section{Evren ve Örneklem}

Araştırmanın evreni, Elazığ Gençlik Merkezi'ni son bir yılda ziyaret eden 1750 kişiden oluşmaktadır. Araştırmada örnekleme dahil edilmesi gereken kişi sayısı $n=\frac{N \cdot \sigma^{2} \cdot z^{2}}{d^{2} \cdot(N-1) \cdot+z^{2} \cdot \sigma^{2}}$ formülü yardımı ile hesaplanmıştır (Özdamar, 2003). Hesaplamalar sonucunda örnekleme 316 kişinin dahil edilmesi sonucuna ulaşılmıştır. Araştırmada "Kolayda örneklem” yöntemiyle 350 kişiye soru formları uygulanmış ve bunların 344 'ü değerlendirmeye dâhil edilmiştir.

\section{Verilerin Analizi}

Verilerin analizi IBM SPSS 25 paket programı kullanılarak gerçekleştirilmiştir. Öncelikle verilerin güvenirliği Cronbach Alpha yöntemi ile test edilmiş ve $\alpha=0,960$ olarak bulunmuştur. Bulunan $\alpha$ değeri 0,70 'in üzerinde olduğu için çalışmanın güvenilir düzeyde olduğu belirlenmiş ve analizler gerçekleştirilmiştir. İlk olarak katılımcıların demografik bilgilerine ait frekans (n) ve yüzde (\%) değerler sunulmuştur. Demografik değişkenlere ait kategoriler arasında ölçek puanları bakımından farklılıkları incelemek için verilerin normal dağılıma uygunluk gösterip göstermediği Shapiro-Wilk testi ile incelenmiştir. Verilerin normal dağllıma uygunluk gösterdikleri tespit edilmiş ve iki kategori içeren değişkenlerin ölçek puanları ile karşılaştırılmasında bağımsız örneklem $T$ testi, ikiden çok kategori içeren değişkenlerin ölçek puanları ile karşılaştırılmasında tek yönlü varyans analizi (One-Way ANOVA) yöntemleri kullanılarak karşılaştırmalar yapılmıştır. Tek yönlü varyans analizi sonucunda farklılık tespit edilmesi durumunda; post-hoc yöntemlerden Bonferroni Testi kullanılarak farkl11ı̆̆ın hangi kategori ya da kategorilerden kaynaklandığı tespit edilmiştir. İki sürekli değişkenin karşılaştırılmasında; öncelikle normal dağılıma uygunlukları incelenmiştir. Verilerin normal dağılıma uygunluk gösterdiği tespit edilmiştir ve bu sebeple Pearson korelasyon katsayısı kullanılarak analizler gerçekleştirilmiştir. Çalışmada $\alpha=0.05$ olarak alınıştır. 


\section{Bulgular}

Tablo 1: Katılımcıların Demografik Bilgileri

\begin{tabular}{|c|c|c|}
\hline & $\mathbf{n}$ & $\%$ \\
\hline \multicolumn{3}{|l|}{ Cinsiyet } \\
\hline Erkek & 185 & 53,8 \\
\hline Kadın & 159 & 46,2 \\
\hline \multicolumn{3}{|l|}{ Yaş } \\
\hline 7-12 Yaş & 47 & 13,7 \\
\hline 13-18 Yaş & 116 & 33,7 \\
\hline 19-24 Yaş & 135 & 39,2 \\
\hline 25 Yaş ve üzeri & 46 & 13,4 \\
\hline \multicolumn{3}{|l|}{ Aile gelir durumu } \\
\hline 1600 TL ve altı & 68 & 19,8 \\
\hline $1601-2500$ TL aras1 & 72 & 20,9 \\
\hline $2501-3000 \mathrm{TL}$ & 66 & 19,2 \\
\hline $3001-4000 \mathrm{TL}$ & 47 & 13,7 \\
\hline 4001 TL ve üzeri & 91 & 26,5 \\
\hline \multicolumn{3}{|l|}{ Öğrenim durumu } \\
\hline İlköğretim & 44 & 12,8 \\
\hline Ortaokul & 47 & 13,7 \\
\hline Lise & 79 & 23,0 \\
\hline Lisans & 127 & 36,9 \\
\hline Lisansüstü & 47 & 13,7 \\
\hline \multicolumn{3}{|l|}{ Ziyaret sıklığı } \\
\hline Haftada bir-iki gün & 61 & 17,7 \\
\hline Haftada üç-beş gün & 226 & 65,7 \\
\hline Ayda birkaç gün & 27 & 7,8 \\
\hline Yilda birkaç gün & 30 & 8,7 \\
\hline \multicolumn{3}{|l|}{ Çalışma durumu } \\
\hline Evet & 62 & 18,0 \\
\hline Hayır & 282 & 82,0 \\
\hline
\end{tabular}

Tablo 1 incelendiğinde katılımcılar cinsiyet değişkenine göre 185 'i $(\% 53,8)$ erkek, 159 'u $(\% 46,2)$ kadın olduğu görülmektedir. Bireylerin yaş değişkenine göre 47'si (\%13,7) 07-12 yaş, 116's1 $(\% 33,7) 13-18$ yaş, 135 'i $(\% 39,2) 19-27$ yaş,46's1 $(\% 13,4) 25$ yaş üzeri olarak dağılım göstermektedir. Katılımcılar gelir durumu değişkenine göre 68'i $(\% 19,8) 1600$ tl ve altı, 72'si $(\% 20,9)$ 1601-2500 tl, 66's1 (\%19,2) 2501-3000 tl, 47'si (\%13,7) 3001-4000 tl, 91'i $(\% 26,5) 4001$ tl ve üzeri olduğu belirlenmiştir. Katılımcıların eğitim durumu değişkenine göre 127'si $(\% 36,9)$ lisans, 79'sı (\%23) lise, 47'si $(\% 13,7)$ ortaokul olarak dağ 11 ım göstermektedir. Katılımcılar çalışma durumuna göre 62'si $(\% 18,3)$ çalışıyorum, 282'si (\%82,0) çalışıyorum olarak dağılım göstermektedir.

Tablo 2: Katılımcıların Cinsiyetleri Bakımından Ölçek Puanlarının Karşılaştırılması

\begin{tabular}{llllcc}
\hline Boyut & Cinsiyet & Ort. & SS. & t & p \\
\hline Katılım & Erkek & 4,04 & 0,83 & 0,202 & 0,840 \\
\multirow{3}{*}{ Gönüllüllük } & Kadın & 4,02 & 0,72 & & \\
\multirow{4}{*}{ Toplam } & Erkek & 3,97 & 0,94 & 0,565 & 0,573 \\
& Kadın & 3,92 & 0,86 & & \\
& Erkek & 4,03 & 0,83 & 0,300 & 0,764 \\
\hline
\end{tabular}


Tablo 2 Katılımcıların cinsiyetleri bakımından ölçek puanları bağımsız örneklem $\mathrm{T}$ testi ile karşılaştırılmıştır. Karşılaştırmalar sonucunda; katılım $(p=0,202)$, gönüllülük $(p=0,565)$ ve toplam puanlar $(\mathrm{p}=0,300)$ arasında istatistiksel olarak anlamlı farklılık meydana gelmediği görülmüştür.

Tablo 3: Katılımcıların Yaş Grupları Bakımından Ölçek Puanlarının Karşılaştırılması

\begin{tabular}{llllccc}
\hline Boyut & Yaş G.** & Ort. & SS. & F & p & Farklılık \\
\hline \multirow{5}{*}{ Katılım } & A & 4,33 & 0,36 & & & \\
& B & 3,88 & 0,88 & 4,193 & $0,006^{*}$ & A>B,C,D \\
& C & 4,08 & 0,75 & & & \\
\hline \multirow{5}{*}{ Gönüllülük } & D & 3,96 & 0,85 & & & \\
& A & 4,29 & 0,55 & & \\
& B & 3,74 & 0,99 & 4,724 & $0,003^{*}$ & A>B,C,D \\
& C & 4,02 & 0,92 & & & \\
\hline \multirow{5}{*}{ Toplam } & D & 3,89 & 0,81 & & & \\
& A & 4,32 & 0,32 & & & \\
& B & 3,85 & 0,89 & & & \\
& C & 4,07 & 0,76 & & & \\
\hline
\end{tabular}

$* \mathrm{p}<0,05$

**A: 7-12 Yaş

B: 13-18 Yaş

C: $19-24$ Yaş

D: 25 Yaş ve üzeri

Tablo 3 Bireylerin yaşları ile ölçek puanları tek yönlü Anova testi ile karşılaştırılmıştır. Karşılaştırmalar sonucunda; katılım $(p=0,006)$, gönüllülük $(p=0,003)$ ve toplam puanlar $(p=0,004)$ anlamlı farklılık olduğu görülmüştür. Farklılığın hangi gruplar ve ya gruplardan kaynaklandığını belirlemek için post-hoc yöntemlerden Bonferroni testi ile gruplar ikişerli olarak karşılaştırılmıştır. 712 Yaş aralığındaki bireylerin diğer üyelere oranla daha fazla katılım, gönüllülük ve toplam puanlara sahip oldukları saptanmıştır.

Tablo 4: Katılımcıların Aile Gelir Durumları Bakımından Ölçek Puanlarının Karşılaştırılması

\begin{tabular}{lcccccc}
\hline Boyut & Aile Gelir ** & Ort. & SS. & F & p & Farklılı \\
\hline \multirow{5}{*}{ Katılım } & A & 3,99 & 0,95 & & & \\
& B & 4,38 & 0,48 & & & \\
& C & 4,03 & 0,89 & 5,235 & $<0,001^{*}$ & B,C $>$ A,D,E \\
& D & 3,85 & 0,67 & & & \\
Gönüllülük & E & 3,89 & 0,72 & & & \\
& A & 4,09 & 0,98 & & & \\
& B & 4,25 & 0,78 & & 0,001 & B > A,C,D,E \\
& C & 3,89 & 0,96 & 4,609 & & \\
Toplam & D & 3,80 & 0,93 & & & \\
& E & 3,71 & 0,80 & & & A,B,C $>$ D,E \\
& A & 4,01 & 0,95 & & & \\
\hline
\end{tabular}

$* \mathrm{p}<0,05$

**A: $1600 \mathrm{TL}$ ve alt1

B: $1601-2500 \mathrm{TL}$ aras1 
C: $2501-3000 \mathrm{TL}$

D: $3001-4000 \mathrm{TL}$

E: 4001 TL ve üzeri

Tablo 4 Katılımcıların aile gelir durumları bakımından ölçek puanları tek yönlü Anova ile karşılaştırılmıştır. Karşılaştırmalar sonucunda; katılım $(p<0,001)$, gönüllülük $(p=0,001)$ ve toplam puanlar $(\mathrm{p}=0,001)$ arasında istatistiksel olarak anlamlı farklılaşma meydana geldiği görülmüştür. Farklılığın hangi kategori ya da kategorilerden kaynaklandığını tespit edebilmek için post-hoc yöntemlerden Bonferroni testi ile gruplar ikişerli olarak karşılaştırılmıştır. Bonferroni testi sonucunda; 1601-3000 TL gelir düzeyindeki katılımcıların en yüksek katılım puanlarına; 1601-2500 TL gelir düzeyindeki katılımcıların en yüksek gönüllülük puanlarına ve 3000 TL'nin altında gelir düzeyindeki katılımcıların diğer katılımcılardan daha yüksek toplam puanlara sahip oldukları saptanmıştır.

Tablo 5: Katılımcıların Öğrenim Durumları Bakımından Ölçek Puanlarının Karşılaştırılması

\begin{tabular}{lcccccc}
\hline Boyut & Yaş G. & Ort. & SS. & F & p & Farklılık \\
\hline \multirow{5}{*}{ Katılım } & A & 4,35 & 0,37 & & & \\
& B & 3,74 & 0,95 & & & \\
& C & 4,03 & 0,78 & 6,359 & $<0,001^{*}$ & A,C,D>B>E \\
& D & 4,15 & 0,74 & & & \\
\hline \multirow{5}{*}{ Gönüllülük } & E & 3,72 & 0,82 & & & \\
& A & 4,36 & 0,49 & & & \\
& B & 3,48 & 1,09 & & & \\
& C & 3,81 & 0,93 & 9,586 & $<0,001^{*}$ & A,D $>$ B,C,E \\
& D & 4,16 & 0,80 & & & \\
Toplam & E & 3,67 & 0,91 & & & \\
& A & 4,35 & 0,31 & & & \\
& B & 3,68 & 0,96 & & & \\
& C & 3,98 & 0,78 & 7,329 & & \\
& D & 4,15 & 0,74 & & & \\
\hline
\end{tabular}

$* \mathrm{p}<0,05$

**A: İlköğretim

B: Ortaokul

C: Lise

D: Üniversite

E: Mezun

Tablo 5 Katılımcıların öğrenim durumları bakımından ölçek puanları tek yönlü Anova ile karşılaştırılmıştır. Karşılaştırmalar sonucunda; katılım $(p<0,001)$, gönüllülük $(p<0,001)$ ve toplam puanlar $(\mathrm{p}<0,001)$ arasında anlamlı farklılaşma olduğu belirlenmiştir. Farklılığın hangi kategori ya da kategorilerden kaynaklandığını tespit edebilmek için post-hoc yöntemlerden Bonferroni testi ile gruplar ikişerli olarak karşılaştırılmıştır. Bonferroni testi sonucunda; ilköğretim, lise ve üniversite öğrenim durumuna sahip katılımcıların en yüksek katılım puanlarına; ilköğretim ve mezun durumundaki öğrencilerin ise en yüksek gönüllülük ve toplam puanlara sahip oldukları saptanmıştır. 
Tablo 6: Katılımcıların Ziyaret Sıklıkları Bakımından Ölçek Puanlarının Karşılaştırılması

\begin{tabular}{lcccccc}
\hline Boyut & Yaş G. & Ort. & SS. & F & p & Farklılık \\
\hline \multirow{5}{*}{ Katılım } & A & 3,92 & 0,63 & & & \\
& B & 4,17 & 0,73 & 11,446 & $<0,001^{*}$ & A,B $>$ C,D \\
& C & 3,35 & 0,81 & & & \\
\hline \multirow{4}{*}{ Gönüllülük } & D & 3,83 & 0,98 & & & \\
& A & 4,02 & 0,71 & & $<0,001^{*}$ & A,B $>$ C,D \\
& B & 4,06 & 0,83 & 10,172 & & \\
\hline \multirow{5}{*}{ Toplam } & C & 3,16 & 1,13 & & & \\
& D & 3,63 & 1,15 & & & \\
& A & 3,94 & 0,63 & & & \\
& B & 4,15 & 0,73 & 11,498 & $<001^{*}$ & A,B $>$ C,D \\
& C & 3,30 & 0,87 & & & \\
\hline
\end{tabular}

$* \mathrm{p}<0,05$

**A: Haftada bir gün

B: Haftada birkaç gün

C: Ayda birkaç gün

D: Yılda birkaç gün

Tablo 6 Katılımcıların ziyaret sıklıkları bakımından ölçek puanları tek yönlü Anova ile karşılaştırılmıştır. Karşılaştırmalar sonucunda; katılım $(p<0,001)$, gönüllülük $(p<0,001)$ ve toplam puanlar $(\mathrm{p}<0,001)$ anlamlı farklılık olduğu tespit edilmiştir. Farklılığın hangi kategori ya da kategorilerden kaynaklandığını tespit edebilmek için post-hoc yöntemlerden Bonferroni testi ile gruplar ikişerli olarak karşılaştırılmıştır. Haftada bir gün ya da haftada birkaç gün ziyaret eden bireylerin diğer bireylere oranla daha yüksek oranda katılım, gönüllülük ve toplam puanlara sahip oldukları saptanmıştır.

Tablo 7: Katılımcıların Çalışma Durumları Bakımından Ölçek Puanlarının Karşılaştırılması

\begin{tabular}{lccccc}
\hline Boyut & $\begin{array}{c}\text { Çalışma } \\
\text { Durumları }\end{array}$ & Ort. & SS. & T & p \\
\hline Katılım & Evet & 3,81 & 0,93 & $-2,195$ & $0,031^{*}$ \\
& Hayır & 4,08 & 0,74 & & \\
Gönüllülük & Evet & 3,69 & 1,04 & $-2,157$ & $0,034^{*}$ \\
\multirow{2}{*}{ Toplam } & Hayır & 4,00 & 0,86 & & \\
& Evet & 3,78 & 0,92 & $-2,263$ & $0,026^{*}$ \\
& Hayır & 4,06 & 0,75 & & \\
\hline
\end{tabular}

$* \mathrm{p}<0,05$

Tablo 7 Katılımcıların çalışma durumları bakımından ölçek puanları bağımsız örneklem T testi ile karşı1laştırılmıştır. Karşılaştırmalar sonucunda; katılım $(\mathrm{p}=0,031)$, gönüllülük $(\mathrm{p}=0,034)$ ve toplam puanlar $(\mathrm{p}=0,026)$ anlamlı farklılık olduğu tespit edilmiştir. Çalışmayan üyelerin çalışanlara oranla daha yüksek katılım, gönüllülük ve toplam puanlara sahip oldukları saptanmıştır

Tablo 8: Ölçek Boyutları Arasındaki İlişki Varlığı İncelemesi

\begin{tabular}{lll}
\hline Katılım & Gönüllülük \\
\hline & $\mathrm{r}$ & 0,860 \\
& $\mathrm{p}$ & $<0,001^{*}$ \\
\hline
\end{tabular}

$* \mathrm{p}<0,05$ 
Tablo 8 Katılımcıların katılım ve gönüllülük puanları arasındaki ilişki varlığı Pearson korelasyonu kullanılarak incelenmiştir. İnceleme sonucunda; katılım ve gönüllülük puanları arasında pozitif yönlü, kuvvetli bir ilişki olduğu $(\mathrm{p}<0,001 ; \mathrm{r}=0,860)$ tespit edilmiştir.

\section{Tartışma ve Sonuç}

Araştırma kapsamında bulunan gençlerin cinsiyetlerine göre gençlik merkezleri aktivitelerine dair tutumlarının gönüllülük, katılım boyutlarında ve ölçek toplamında anlamlı bir farklılaşma meydana gelmediği belirlenmiş̧tir. Yapılan bir araştırmadan elde edilen sonuca göre Gençlik merkezindeki serbest zaman faaliyetlerine katılım sağlayan kişilerin cinsiyet değişkeni ile sosyal beceri alt boyutlarından duyuşsal kontrol, duyuşsal anlatımcılık, duyuşsal duyarlılık, sosyal kontrol ve sosyal beceri, sosyal duyarlılık, sosyal anlatımcılık, toplam kadın ve erkek puan ortalamaları arasında istatistiksel olarak anlamlı düzeyde farklılığın olmadığı tespit edilmiştir. (Keleş,2017) Farklı bir çalışmada Ataç, (2018) tarafından yapılmış ve gençlerin cinsiyetlerine göre gençlik merkezleri faaliyetlerine ilişkin tutumlarının gönüllülük, katılım boyutlarında anlamlı bir şekilde farklılaşma olmadığı görülmüştür. Buna neden olarak katılımcı gençlerin farklı sosyo-demografik özelliklere sahip olmalarından kaynaklandığı düşünülmektedir.

Araştırmaya katılan gençlerin aile gelir durumlarının bu etkinliklere ilişkin tutumlarının katılım ve gönüllülük boyutları ile ölçeğin toplam puanları arasında anlamlı bir farklılaşma olduğu görülmüştür. Buna göre gelir durumu $3000 \mathrm{TL}$ ve altındaki gençlerin gönüllülük ve katılım boyutlarında en yüksek puanlara sahip olduğu görülmüştür. Örteş (2010) tarafindan yapılan araştırma sonucunda katılımcılardan her dört kişiden birinin serbest zamanlarını değerlendirmelerinde ekonomik durumlarının engel teşkil ettiği, dörtte üçünün ise ekonomik şartların serbest zamanlarını değerlendirme engel teşkil etmediği belirtmiştir. Çalışmamızda gelir durumu daha düşük seviyede olan gençlerin katılım ve gönüllülük puanlarının daha yüksek olduğu göz önüne alındığı zaman gençlerin tamamen gönüllülük esasına göre bu aktivitelere katıldıkları ve motivasyonlarını geliştirerek gençlik merkezlerindeki aktivitelerde yer aldıkları söylenilebilir.

Gençlerin eğitim durumları ile gençlik merkezlerindeki etkinliklere ilişkin tutumları arasında anlamlı bir farklılık olduğu ve eğitim seviyesi yükseldikçe gençlerin aktivitelere karşı katılımlarının daha fazla olduğu görülmüştür. Fişne (2017) tarafından yapılan ve katılımcıların eğitim durumlarına göre değerlendirilen araştırmada en yüksek motivasyon seviyesine üniversitede eğitim gören ögrencilerin sahip olduğu ayrıca sporda gönüllülük motivasyonunun istatistiksel olarak anlamlı bir farklılaşma gösterdiği belirlenmiştir. Çalışma, eğitim seviyesinin yüksekliğine bağlı olarak değerlendirildiğinde araştırmamızla aynı yönde sonuç vermiştir. Eğitim seviyesi yüksek olan gençlerin gençlik merkezindeki etkinliklere daha fazla katılım sağlamalarının nedeni olarak gençlik merkezlerinde lise mezunu olan ve üniversiteye hazırlanan ya da üniversitede eğitim gören gençlere yönelik düzenlenen kursların ve aktivitelerin daha yoğun şekilde olduğu düşünülmektedir.

Haftada bir gün ya da haftada birkaç gün ziyaret eden katılımcıların diğer katılımcılara göre daha yüksek katılım ve gönüllülük puanlarına sahip olduğu görülmüştür. Sönmezoğlu vd., (2014) tarafından yapılan bir çalışmada bireylerin gençlik merkezlerine üyelik zamanları uzadıkça ve bu merkezlere gitme sıklığı fazlalaştıkça eğitim ve psikolojik boyuttaki tatmin düzeylerinin de aynı doğrultuda yükseldiği belirtilmiştir. Araştırma çalışmamızla aynı yönde sonuç vermiştir. Herhangi bir işte çalışmayan üyelerin çalışan üyelere göre ölçeğin gönüllülük ve katılım alt boyutlarından elde ettikleri puanların daha yüksek oldukları görülmüştür. Çalışmayan üyelerin bir meşguliyeti ya da gençlik merkezine gitmelerine engel teşkil edecek bir durumlarının söz konusu olmadığı, böylece bu merkezdeki etkinliklere daha fazla zaman ayırarak katılım sağlamalarından dolayı elde ettikleri puanların daha yüksek olduğu, gençlik merkezine giden üyelerin bu merkezdeki aktivitelere katılım düzeyleri arttıkça gönüllülük durumlarının da artış olduğu söylenilebilir.

Turkish Studies - Social, 15(5) 
Sonuç olarak: Bireylerin cinsiyetlerinin gençlik merkezlerinde etkinliklerine yönelik tutumlarında anlamlı bir farklılık meydana getirmediği, maddi durumu daha düşük seviyede olan bireylerin gençlik merkezlerindeki etkinliklere yönelik tutumlarının daha yüksek olduğu ve bu etkinliklere katılmalarında ekonomik durumlarının önemli bir etken olmadığı görülmüştür. Gençlik merkezinde ki etkinliklere eğitim seviyesi daha yüksek olan bireylerin daha fazla katılım sağladıkları, aktivitelere katılım sağlayan bireylerin daha fazla sıklıkta gençlik merkezlerine gittikleri, herhangi bir işte çalışmayan bireylerin bir meşguliyeti ya da gençlik merkezine gitmelerine engel teşkil edecek bir durumlarının söz konusu olmadığı, böylece bu merkezdeki etkinliklere daha fazla zaman ayırarak gönüllü olarak katılım sağladıkları, bireylerin gençlik merkezinde ki aktivitelere katılım düzeyleri arttıkça gönüllülük durumlarının da bir artış olduğu görülmüştür.

\section{Kaynakça}

Akın, M. H. (2014). Gençlik toplumsallaşmasında akran ve arkadaşlık grupları. Gençlik Araştırmaları Dergisi, 2(4), 10-21.

Ataç, Ö., Sadık, R. \& Tezcan Kardaş, N. (2018). Gençlik merkezleri faaliyetlerine yönelik tutum ölçeği geliştirilmesi: güvenirlik ve geçerlik çalışması. Uşak Üniversitesi Sosyal Bilimler Dergisi, 11(C-IASOS Özel Say1s1), 92-97.

Ataç, Ö. (2018). Gençlerin gençlik merkezleri faaliyetlerine ilişkin tutumlarının incelenmesi. Yüksek Lisans Tezi. Düzce Üniversitesi Sağlık Bilimleri Enstitüsü.

Atlı, Ç. (2006). Okul öncesi eğitimi alan 6 yaş çocuklarının sosyal ilişkileri anlamlandırmasının incelenmesi. Yüksek Lisans Tezi. Hacettepe Üniversitesi Sosyal Bilimler Enstitüsü.

Aycan, A. (2005). Gençlik merkezlerinin örgütsel etkililik ve hizmet kalitesinin değerlendirilmesi. Marmara Üniversitesi. Sağlık Bilimleri Enstitüsü. Doktora Tezi.

Dermez, H.G. (2008). İlköğretim 4. ve 5. sınıf öğrencilerinin sosyal beceri düzeylerinin bazı değişkenler açısından incelenmesi. Yüksek Lisans Tezi, Afyon Kocatepe Üniversitesi Sosyal Bilimler Enstitüsü.

Fişne, M. (2017). Kişilik özelliklerinin sporda gönüllülük motivasyonu üzerine etkisi: uluslararası spor organizasyonlarında görev alan gönüllülere yönelik bir araştırma. Cumhuriyet Üniversitesi. Sosyal Bilimler Enstitüsü. Doktora Tezi.

Geçtan, E. (2019). Ergenlikten yetişkinliğe geçiş dönemi olarak gençlik. Ankara University Journal of Faculty of Educational Sciences (JFES), 14 (1), 91-100.

Gür, B. S., Dalmış, İ. K., \& Nur-Çelik, Z. B. (2012). Türkiye'nin Gençlik Profili. Ankara: Pelin Ofset

Gürses, F. \& Gürses, H. B. (1997). Dünya'da ve Türkiye'de Gençlik, Toplumsal Dönüşüm Yayınları.

Kara, S. (2013). Hz. Peygamberin Elinde Şekillenen İdeal Gençlik. Gençlik Araştırmaları Dergisi, 1(2), 8-29.

Kelleş F. (2017). Gençlik merkezindeki serbest zaman etkinliklerine katılan bireylerin sosyal beceri düzeylerinin bazı demografik değişkenlere göre incelenmesi: Adıyaman İli Örneği. Bartın Üniversitesi. Eğitim Bilimleri Enstitüsü. Yüksek Lisans Tezi.

MEB. Aile Tüketici Hizmetleri. (2011). Gençlere Sosyal Hizmet Veren Kurum ve Kuruluşlar. 
Örteş, G. (2010). Gençlik ve spor il müdürlüklerine bağlı gençlik merkezlerinin 15-26 yaş arasındaki gençler tarafından bilinirlik düzeyi (Kocaeli İli Uygulaması).Marmara Üniversitesi. Sağl1k Bilimleri Enstitüsü. Yüksek Lisans Tezi.

Özbay, F. (2015). Dünden Bugüne Aile, Kent, Nüfus. 1. Bask1, İletişim Yayınları.

Özdamar, K. (2003). Modern bilimsel araştırma yöntemleri: araştırma planlama, toplum ve örnek seçimi, güç analizi, proje hazırlama, veri toplama, veri analizi, bilimsel rapor yazımı. Kaan Kitabevi.

Sönmezoğlu, U., Polat, E., \& Aycan, A. (2014). Gençlik merkezi üyeleri ve bazı değişkenlere göre serbest zaman tatmin düzeyleri. International Journal of Sport Culture and Science, 2(Special Issue 1), 219-229. 